\title{
A New Approach to the Fabrication of "Smart" Near-Surface Nanostructure Composites
}

\author{
Laurence Gea', S. Honda', L. A. Boatner', T. E. Haynes', B. C. Sales ${ }^{1}$, F. A. Modine ${ }^{1}$, A. Meldrum', J. \\ D. Budai ${ }^{1}$, and L. Beckers ${ }^{2}$ \\ 'Solid State Division. Oatk Ridge National Laboratory, Oak Ridge, Tennessee 37831-6056 \\ -ForshungzentrumJuelich, Juelich, Germany
}

To be published in:

Surface-Controlled Nanoscale Materials

for High-Added-Value Applications

ed. by K. E. Gonsalves, M.-I. Baraton, J. X. Chen, and J. A. Akkara

Proceedings of the 1997 Fall Meeting of the MRS, Boston, MA

Materials Research Society, San Franciseo, California, 1997

warrendale, $P A$

"The submitted manuscript has been authored by a contractor of the U.S. Government under contract DE AC05-96OR22464. Accordingly, the U.S.

(jovernmene retains a nonexclusive, royalcy-free lkense wo publish or reproduce the published form of chis contribution, or allow others to do so, for U.S.

Givernmenpurposes."

\section{6}

-2EOEIVED

FFR 251998

O STI

\author{
January 1998

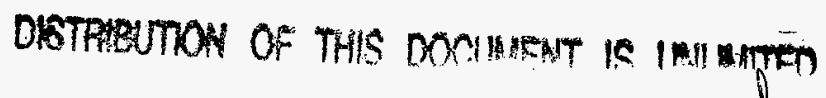 \\ Preparedby \\ SolidStateDivision \\ Oak Ridge National Laboratory \\ P.O. Box 2008 \\ Oak Ridge, Tennessee 37831-6056 \\ managed by \\ LOCKHEED MARTIN ENERGY RESEARCHCORP \\ for the \\ U.S.DEPARTMENTOFENERGY \\ under contract DE-AC05-96OR22464
}

This research was sponsored by the Oak Ridge National Laboratory, managed by Lockheed Martin Energy Research Corp., for the U.S. Department of Energy, under contract DE-AC05-96OR22464. 


\section{DISCLAIMER}

This report was prepared as an account of work sponsored by an agency of the United States Government. Neither the United States Government nor any agency thereof, nor any of their employees, makes any warranty, express or implied, or assumes any legal liability or responsibility for the accuracy, completeness, or usefulness of any information, apparatus, product, or process disclosed, or represents that its use would not infringe privately owned rights. Reference herein to any specific commercial product, process, or service by trade name, trademark, manufacturer, or otherwise does not necessarily constitute or imply its endorsement, recommendation, or favoring by the United States Government or any agency thereof. The views and opinions of authors expressed herein do not necessarily state or reflect those of the United States Government or any agency thereof. 


\title{
A NEW APPROACH TO THE FABRICATION OF "SMART" NEAR-SURFACE NANOSTRUCTURE COMPOSITES
}

\author{
LAURENCE GEA, S. HONDA, L. A. BOATNER, T. E. HAYNES, B. C. SALES, F. A. \\ MODINE, A. MELDRUM, J. D. BUDAI, L. BECKERS * \\ Solid State Division, Oak Ridge National Laboratory, Oak Ridge, TN 37831, USA, \\ * Forschungzentrum Juelich, Germany
}

\section{ABSTRACT}

A new method for the formation of "smart" near-surface nanoscale composites has been developed. In this approach, small precipitates of active phases are embedded in the near-surface region of the material that is to be modified by a combination of ion implantation and thermal processing. The dispersion, concentration, and microstructure of the nanocrystals formed in the substrate material can be tailored through a careful choice of processing parameters - making this approach well suited to high-value-added, high-technology applications. The applicability of this approach to forming "smart" surfaces on otherwise inactive materials was established in the case of $\mathrm{VO}_{2}$ precipitates which were embedded in $\mathrm{Al}_{2} \mathrm{O}_{3}$ single crystals to create a medium suitable for optical applications - including optical data storage. Most recently, this concept has been extended to the fabrication of magnetic-field-sensitive nanostructured surfaces by forming magnetostrictive precipitates of materials such as $\mathrm{Ni}$ or $\mathrm{RFe}_{2}$ (with $\mathrm{R}=\mathrm{Tm}, \mathrm{Tb}, \mathrm{Sm}$ ) that are embedded in various single-crystal-oxide hosts. These nanostructured, active surface composites have been characterized using XRD, RBS, TEM, and magneto-optical techniques.

\section{INTRODUCTION}

A new approach to the fabrication of "smart" nanocomposite systems has been developed by using ion implantation, followed by a thermal treatment, to embed nanocrystals of an "active" material in the near-surface region (10-100 nm) of a single crystal or thin film [1]. Through a careful choice of the implantation parameters (i.e., dose, energy, temperature) and of the annealing conditions (i.e., temperature, time, atmosphere) the size, dispersion, and depth location of the nanocrystals can be controlled. Furthermore, the geometry of the system ensures that the active nanophase precipitates are protected against environmental degradation.

The concept of embedded "smart" nanocrystals was demonstrated by the authors in previous work $[1,2]$, through the fabrication of a $\mathrm{VO}_{2} / \mathrm{Al}_{2} \mathrm{O}_{3}$ nanocomposite system that is capable of controlling the transmission of infra-red radiation. The vanadium dioxide nanocrystals, which were formed after ion implantation of vanadium and oxygen and annealing at 700 to $900^{\circ} \mathrm{C}$, exhibit the thermally induced semiconducting-to-metal phase transition observed in the bulk and thin film forms. The hysteretic behavior of the phase transition as the temperature of the system is scanned around $\mathrm{T}_{\mathrm{c}} \sim 70^{\circ} \mathrm{C}$ allows the transmitted light to be varied in a sharp and reversible manner making this system suitable for optical storage and other applications.

We have now extended this concept to the fabrication of magnetic-field-sensitive systems. Among the magnetic materials, those capable of inducing large stresses or strains through the magnetostrictive effect are of particular interest (e.g. $\mathrm{TbFe}_{2}[3]$, 
PdFe [4], Terfenol-d [5]) since they can be utilized in a variety of "smart" systems such as actuators, micropositioning devices, sonar, and sensors. The purpose of this work is to study the formation of magnetostrictive nanocrystals in the near-surface region of a variety of optical materials. The ultimate goal is to determine whether it is possible to couple the stress field induced by the magnetostrictive nanocrystals to one or more fundamental properties of the surrounding host material - a magnetically induced change of the host refractive index through the electrooptic effect for example.

In the case of the present work, we present a description of the formation and microstructure of the $\mathrm{Ni} / \mathrm{SrTiO}_{3}$, the $(\mathrm{Fe}+\mathrm{Tb}) / \mathrm{YSZ}$, and the $(\mathrm{Ni}, \mathrm{Fe}, \mathrm{Co}) / \mathrm{BaTiO}_{3}$ systems using single and multiple implants with an emphasis on their magneto-optical properties.

\section{EXPERIMENT}

Room-temperature implantations of $\mathrm{Ni}, \mathrm{Fe}, \mathrm{Tb}$, or $\mathrm{Co}$ were performed on single crystals of $\mathrm{SrTiO}_{3}$ and $\mathrm{Y}_{0.15} \mathrm{Zr}_{0.75} \mathrm{O}_{1.93}(\mathrm{YSZ})$, and thin films of $\mathrm{BaTiO}_{3}$. In the case of coimplantation of two elements (e.g. $\mathrm{Fe}+\mathrm{Tb}$ to form $\mathrm{TbFe}_{2}$ ), the implants were performed at a stoichiometric ratio, and implantation energies in the range of 55 to $300 \mathrm{keV}$ were appropriately calculated and selected to insure the superimposition of both the elemental distributions in the same near-surface region of the substrate. Thermal annealing of the co-implanted specimens was carried out in various atmospheres at temperatures ranging from 700 to $1100^{\circ} \mathrm{C}$ for annealing times of one to two hours. The implanted surfaces were subsequently analyzed using Rutherford backscattering (RBS)/channeling, $x$-ray diffraction techniques, and transmission electron microscopy (TEM). The magnetic properties (magnetization and Curie temperature) were obtained using a magnetometer equipped with a heating stage. Magneto-optical properties were investigated by measurements of the magnetic circular dichroism (MCD) of the composite system. MCD is the magnetically induced difference in the absorption of the left and right circularly polarized light and is proportional to the amount of magnetization that is parallel to the applied magnetic field [6]. The measurements were performed as a function of wavelength and as a function of the applied magnetic field with both the light path and the applied magnetic field perpendicular to the specimen surface.

RESULTS

\section{$\underline{\mathrm{Ni} / \mathrm{SrTiO}_{3}} \underline{\text { surface composites }}$}

$\mathrm{Ni}$ implantation was performed at room temperature on (100)-oriented $\mathrm{SrTiO}_{3}$ at an energy of $120 \mathrm{keV}$. Figure 1 shows the $\theta-2 \theta$ scan for a single crystal of (100) $\mathrm{SrTiO}_{3}$ implanted with $2.10^{17} \mathrm{Ni} . \mathrm{cm}^{-2}$ and annealed in a reducing atmosphere $(4 \%$ hydrogen in argon) for 2 hours at a temperature of $1100^{\circ} \mathrm{C}$. The peak observed at the angle of $52^{\circ}$ corresponds to the (200) reflection of metal $\mathrm{Ni}$ and indicates that the Ni precipitates that are formed are out-of-plane oriented with respect to the $\mathrm{SrTiO}_{3}$ substrate. The magnetization, measured as a function of temperature and at an applied magnetic field of $1 \mathrm{kG}$ (Figure 2), yields a Curie temperature that is very close to that of bulk Ni (631K). This value is also in good agreement with that reported previously for graphitically encapsulated Ni nanocrystals [7]. 


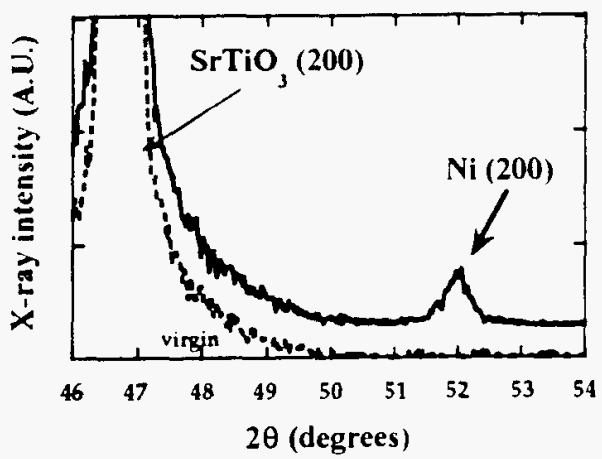

FIGURE 1: $\theta-2 \theta$ scan of $\mathrm{SrTiO}_{3}$ implanted with $2.10^{17} \mathrm{Ni} . \mathrm{cm}^{-2}$ and annealed at $1100^{\circ} \mathrm{C}$ for 2 hours

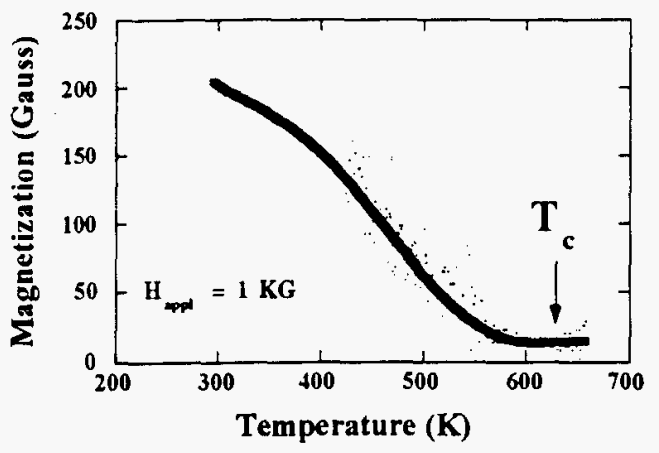

FIGURE 2: magnetization versus temperature for Ni nanocrystals embedded in $\mathrm{SrTiO}_{3}$

Figure 3 shows the magnetic properties of the embedded Ni particles. The magnetization curve taken at room temperature describes a hysteresis as the applied magnetic field is scanned between -2 and $+2 \mathrm{kG}$ (Figure $3 \mathrm{a}$ ) that is indicative of the ferromagnetic behavior. Figure $3 b$ shows the magnetic circular dichroism $(M C D)$ of the same specimen. Because the MCD signal is proportional to the magnetization, it also describes a hysteretic behavior. This demonstrates the concept of magnetically induced light modulation for our nanocomposite systems. The coercive force $\mathrm{H}_{\mathrm{C}}$ obtained from either one of these curves is about a hundred times larger than that of bulk nickel $(0.7$ $G)$. Large coercive forces are often measured in very thin films and have been related to size effects [8]. However, the coercive forces measured on coated nanocrystalline nickel have been shown to be smaller than that of bulk nickel [7] indicating that the origin of the large value measured in our case is related to strains arising from both the lattice mismatch and compressive thermal stresses rather than from size effects. Also, possible contamination from the substrate cannot be ruled out at this point.

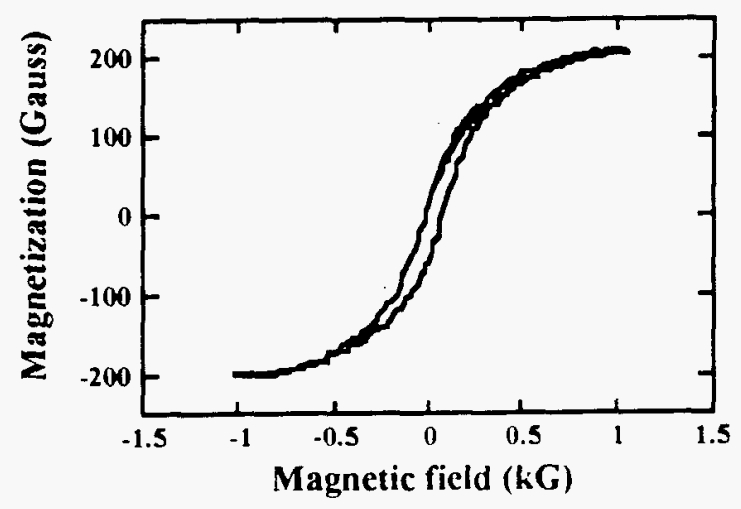

FIGURE 3a: Magnetization curve of a $\mathrm{Ni} / \mathrm{SrTiO}_{3}$ composite taken at $300 \mathrm{~K}$. The curve shows the existence of a ferromagnetic state

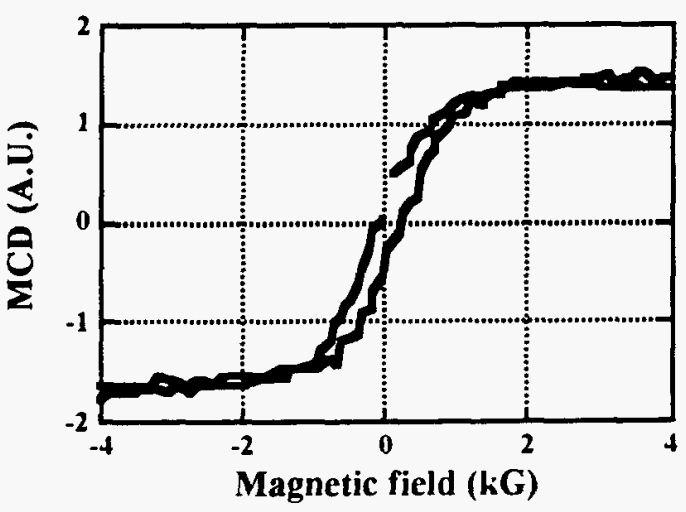

FIGURE 3b: Magnetic circular dichroism for a $\mathrm{Ni} / \mathrm{SrTiO}_{3}$ composite, showing the ferromagnetic behavior of the embedded $\mathrm{Ni}$ nanocrystals 
$\mathrm{TbFe}_{2}$ with a magnetostrictive coefficient $\lambda_{\mathrm{s}} \sim 2000$ ( compared to $\lambda_{\mathrm{s}}=-30$ for $\mathrm{Ni}$ ) is among the most interesting of the magnetostrictive materials. In order to form $\mathrm{TbFe}_{2}$, $\mathrm{Fe}$ and $\mathrm{Tb}$ were co-implanted at a stoichiometric ratio $(\mathrm{Fe}: \mathrm{Tb}=2)$ into (100)- and (110)oriented YSZ single crystals at a temperature of $77 \mathrm{~K}$ and $300 \mathrm{~K}$ respectively. While Fe was implanted over the whole specimen surface, half of the specimen was covered during the Tb implantation. X-ray diffraction (Figure 4) as well as TEM reveals the presence of bcc Fe only in the ( $\mathrm{Tb}+\mathrm{Fe}$ ) implanted region. However, a comparison of the magneto-optical properties of the half of the specimen with that co-implanted with $\mathrm{Tb}$ and $\mathrm{Fe}$ and the other half( only implanted with $\mathrm{Fe}$ ) indicates that the implantation of $\mathrm{Tb}$ plays a role that, however, remains to be clarified. Figure 5 shows the MCD versus wavelength measurement performed on both these specimens after thermal treatment in a reducing atmosphere for 2 hours at $1100^{\circ} \mathrm{C}$. Before the application of a magnetic field, no signal is measured. A large MCD signal is found in the case of the maximum applied field of $7 \mathrm{kG}$ or when the field is switched off $(\mathrm{H}=0)$. It is clear from these results that the dichroism is largest in the case of co-implantation of $\mathrm{Tb}$ and $\mathrm{Fe}$. The MCD signal measured when the applied magnetic field is lowered to zero is indicative of the ferromagnetic character of the embedded Fe particles and is related to the remnant magnetization. As expected from ferromagnetic particles, the MCD taken as a function of the applied magnetic field is hysteretic in both cases. It is not possible at this time to draw any conclusion about the possible presence of another phase since such a phase was not detected via either high-resolution x-ray diffraction or TEM. If $\mathrm{TbFe}_{2}$ nanocrystals are formed, they may be randomly oriented - as observed in Pt-implanted YSZ [9] - or they may be too dilute or too small to be detected by $x$-ray analysis.

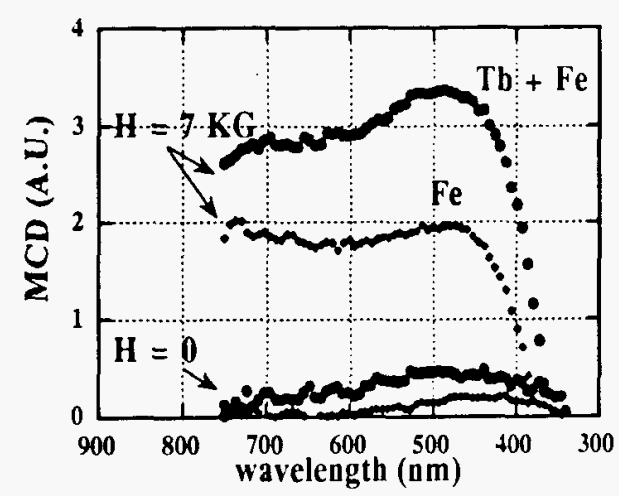

FIGURE 4: magnetic circular dichroism versus wavelength for $\mathrm{Fe}+\mathrm{Tb}$ and $\mathrm{Fe}$-implanted $\mathrm{YSZ}$ after annealing at $1100^{\circ} \mathrm{C}$ for 2 hours

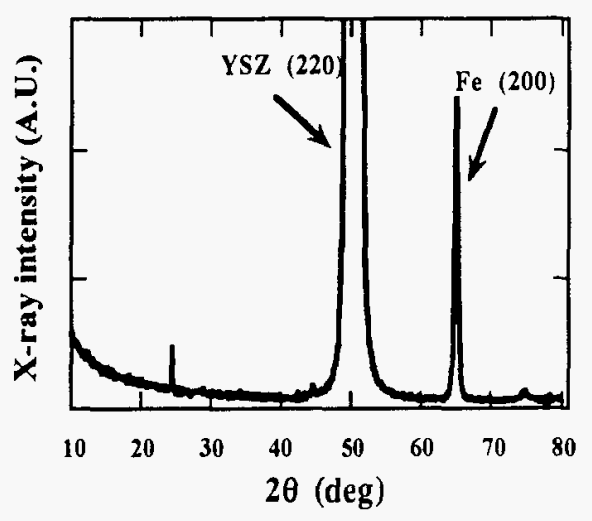

FIGURE 5: $\theta-2 \theta$ scan of $\mathrm{Tb}+\mathrm{Fe}$ implanted YSZ after thermal treatment at $1100^{\circ} \mathrm{C}$ for 2 hours 


\section{Formation of ferromagnetic particles in $\mathrm{BaTiO}_{3}$ thin films}

A significant amount of attention has been devoted to barium titanate due to both its electro-optical and waveguiding properties. Recently, it has been shown [10-11] that composites formed of $\mathrm{BaTiO}_{3}$ and a ferrite $\left(\mathrm{NiFe}_{2} \mathrm{O}_{4}\right.$ or $\mathrm{CoFe}_{2} \mathrm{O}_{4}$ for example) exhibit the magneto-electric effect (i.e. a voltage is magnetically induced in $\mathrm{BaTiO}_{3}$ by the magnetostriction of the ferrite phase through the piezoelectric effect).

The films used in the present study were deposited by pulsed laser deposition, and their microstructure and properties are described elsewhere [12]. RBS/Channeling techniques indicate the surface region that is amorphized by the implantation recrystallizes epitaxially with respect to the underlying non-damaged film on thermal annealing. An excellent dechanneling yield of about $15 \%$ is measured, and compares to the $4 \%$ yield corresponding to the non-implanted specimen.

Figure 6 shows the MCD of thin films of $\mathrm{BaTiO}_{3}$ implanted with $\mathrm{Ni}(\mathrm{a}), \mathrm{Ni}+\mathrm{Fe}$ (b) or $\mathrm{Fe}+\mathrm{Co}(\mathrm{c})$ and annealed at $1100^{\circ} \mathrm{C}$ for 0.5 hour. The MCD behavior is characteristic of the formation of ferromagnetic particles. It is, therefore, possible to embed ferromagnets in $\mathrm{BaTiO}_{3}$ waveguide films. The potential applications for magnetic-field-sensitive composite waveguides are numerous.
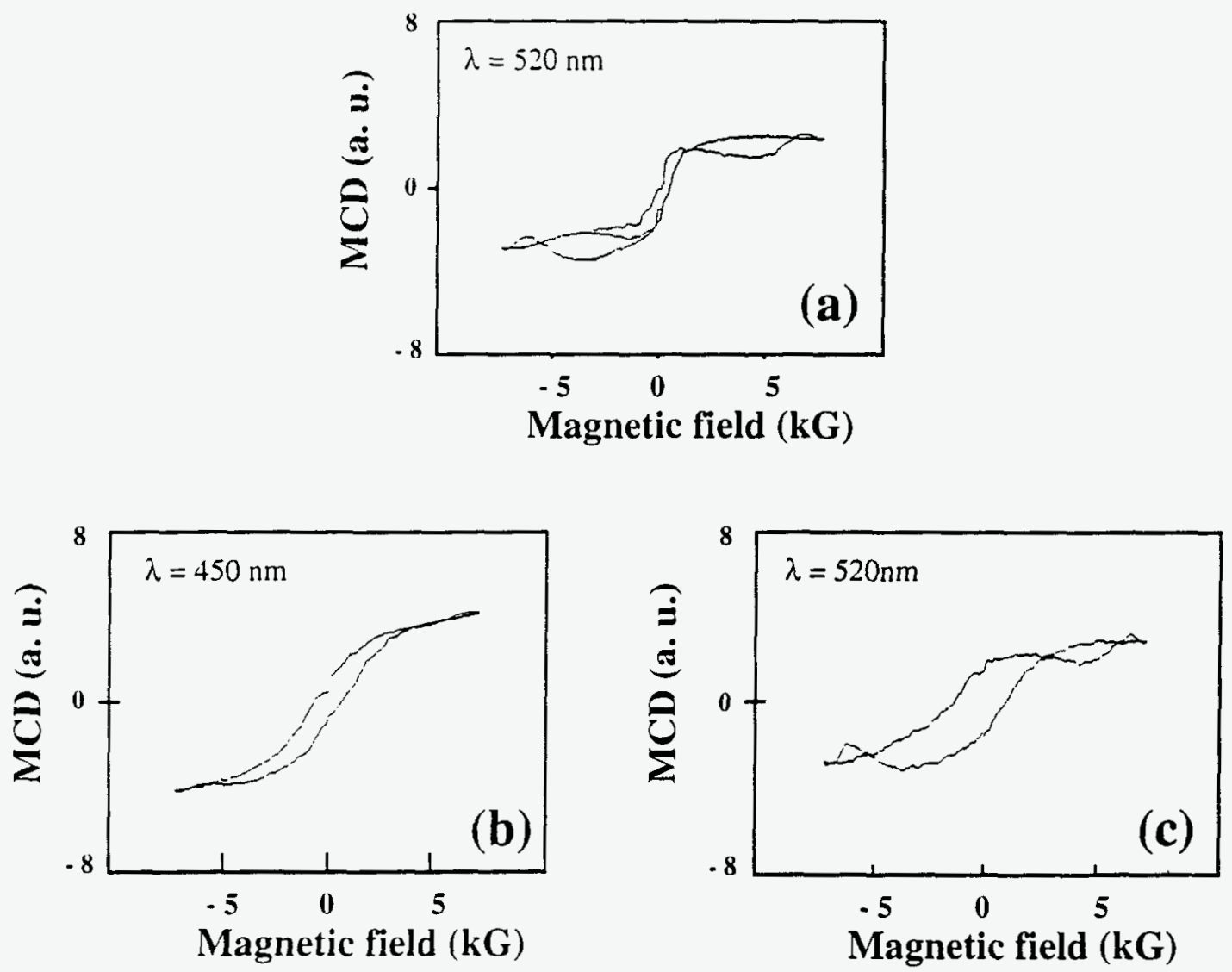

FIGURE 6: Magnetic circular dichroism versus magnetic field of $\mathrm{BaTiO}_{3}$ thin films implanted and annealed for $0.5 \mathrm{~h}$ at $1100^{\circ} \mathrm{C}$ for: (a) dose of $10^{17} \mathrm{Ni}^{-\mathrm{cm}^{-2}}$, annealed in $\mathrm{Ar}+4 \% \mathrm{H}_{2}$; (b) $5.10^{16} \mathrm{Ni} . \mathrm{cm}^{-2}$ and $10^{17} \mathrm{Fe} . \mathrm{cm}^{-2}$, annealed in $\mathrm{O}_{2}$ (c) $5.10^{16} \mathrm{Co} \mathrm{cm}^{-2}$ and $10^{17} \mathrm{Fe} . \mathrm{cm}^{-2}$, annealed in $\mathrm{O}_{2}$. The three curves show the presence of ferromagnetic particles inside the $\mathrm{BaTiO}_{3}$ waveguide. 


\section{SUMMARY}

Magnetic and magnetostrictive nanophase particles can be formed in a variety of substrates using the combined methods of ion implantation and thermal treatment. When the corresponding nanocomposite system is subjected to an applied magnetic field, the intensity of transmitted polarized light varies hysteretically with the magnetization of the embedded magnetic nanocrystals. Further work is needed to form relatively phase-pure precipitates with large magnetostrictive coefficients such as $\mathrm{TbFe}_{2}$ as well as to demonstrate the coupling between the magnetostriction of the nanocrystals and the electro-optical properties of the substrate.

\section{ACKNOWLEDGMENTS}

This research was sponsored by the Division of Materials Sciences, U.S. Department of Energy under Contract No. DE-AC05-960R22464 with Lockheed Martin Energy Research Corp.

\section{REFERENCES}

1. L. A. Gea and L. A. Boatner, Appl. Phys. Lett. 68, (1996) 3081.

2. L. A. Gea, J. D. Budai and L. A. Boatner, to be published.

3. A. E. Clark, AIP Conf. Proc. 18, 1015 (1974).

4. J. E. Schmidt and L. E. Berger, J. Appl. Phys. 55, 1073 (1984).

5. A. E. Clark, J. E. Cullen, O. D. McMasters and E. B. Callen, Am. Inst. Phys. Conf. Proc. 29, 192 (1976).

6. R. Laiho, Phys. Stat. Sol. (b) 69, 579 (1975).

7. H. -J. Hwang, V. P. Dravid, M. H. Teng, J. J. Host, B. R. Elliott, D. L. Johnson and T.

O. Mason, J. Mater. Res. 12, 1076 (1997).

8. R. L. Coren and M. H. Francombe, J. de Phys. 25, 233 (1964).

9. Dong-Zhu Xie, De-Zhang Zhu and De-Xin Cao, J. of Phys. 9, 4377, (1997).

10. I. P. Getman, Sov. Phys. - Dokl. 36, 233 (1991).

11. J Van den Boomgaard and R.A. Born, J. Mat. Sci. 13, 1538 (1978).

12. L. Beckers, J. Schubert, W. Zander, J. Ziesmann, P. Leinenbach, A. Eckau, and Ch. Buchal, J. Appl. Phys., submitted for publication. 
M97009372

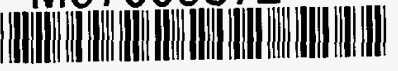

Report Number (14) $\bigcirc$ RNL $/ C P-96051$ CONE-97/201--

Jubl. Date (11) 199801

sponsor Code (18) DOE/ER, XF

JC Category (19) UC-4OO, DOElER

DOE 